\title{
Low Level Laser Therapy -A Review
}

\author{
Dr.P.Surendranath ${ }^{1}$, Dr. Radhika Arjunkumar ${ }^{2}$ \\ ${ }^{1}$ Intern, Dept of Periodontics, Saveetha dental college, Chennai, India) \\ ${ }^{2}$ Senior lecturer, Dept of Periodontics, Saveetha dental college, Chennai, India)
}

\begin{abstract}
Low level laser therapy is defined to supply direct biostimulative light energy to the cells .It has been reported that low-level semiconductor diode lasers could enhance the wound healing process. The periodontal ligament is crucial for maintaining the tooth and surrounding tissues in periodontal wound healing. Low-level semiconductor diode lasers have been used in low-level laser therapy, there have been few reports on their effects on periodontal ligament fibroblasts(PDLFs).Low intensity laser therapy also has stimulating effects on bone cells and can accelerate the repair process of the bone. However still further research needs to be done in laser efficacy for periodontal treatment.
\end{abstract}

Key Words: Biostimulation, Low-level laser therapy, Periodontics, Wound healing.

\section{Introduction}

The principle of using low level laser therapy (LLLT) is to supply direct biostimulative light energy to body cells .Absorbed laser energy causes stimulation of molecules and atoms of cells .Using low-intensity laser radiation on the tissues does not cause rapid and significant increase in tissue temperature.[1] Among various lasers used for periodontal purposes, semiconductor diode lasers are mainly applied in subgingival curettage and periodontal pocket disinfection.[2,3]So far, a concerted effort has been made in the field of root conditioning to improve the outcome of regenerative periodontal therapies by favoring the attachment of the regenerated periodontal structures .

\section{Mechanism Of Action}

The mechanisms of low level laser therapy are complex, but essentially rely upon the absorption of particular visible red and near infrared wave lengths in photoreceptors within sub-cellular components, particularly the electron transport chain within the membranes of mitochondria. [4,5]

Low level laser therapy (LLLT) is also known as laser phototherapy (LPT), biostimulative therapy (BT), Lowintensity laser therapy(LILT).

\section{Low Level Laser Therapy In The Periodontal Inflammatory Process}

The chronic periodontal inflammatory process leads to the destruction of the periodontal ligament, and subsequently, to loss of alveolar bone [3]. It has been reported that LPT is able to reduce gingival inflammation and metalloproteinase 8 expression when applied after scaling and root planning.[6,7,8] Ozawa et al. [9]showed that LLLT significantly inhibits the increase in plasminogen activity induced in human periodontal ligament cells in response to mechanical tensile force. Plasminogen activity is capable of activating latent collagenase, the enzyme responsible for cleaving collagen fibres. LLLT also effectively inhibits PGE2 synthesis.[10]LLLT can modulate the periodontal inflammatory process, especially through reducing PGE2release[11].

\section{Low Level Laser Therapy In Wound Healing}

Periodontal wound healing is necessary when periodontitis and gingivitis , or trauma , have affected the composition and integrity of the periodontal structures.LLLT( laser Periodontal therapy) has also been shown to cause vaso-dilation,with increased local blood flow.This vasoactive effect is of relevance to the treatment of joint inflammation .LLLT causes the relaxation of smooth muscle associated with endothelium.This vasodilation brings in oxygen and also allows for greater traffic of immune cells into tissue.These two effects contribute to accelerated healing.[12,13]

Several invitro studies have shown that LLLT at certain wavelengths may stimulate fibroblast proliferation when certain combinations of exposure parameters and power densities are used[14-23].The range of radiation doses at which stimulation of fibroblast proliferation has been observed is wide $(0.45-60 \mathrm{~J} / \mathrm{cm} 2)$. Of note high dose LPT suppresses both fibroblast proliferation and autocrine production of basic fibroblast growth factor.[24]

LLLT effects on macrophages include increased ability to act as phagocytes, and greater secretion of basic fibroblast growth factor.Macrophages resorb fibrin as part of the demolition phase of wound healing more 
quickly with LLLT, because of their enhanced phagocytic activity during the initial phases of the repair response(for example, 6 hours after trauma).More rapid demolition of the wound establishes conditions necessary for the proliferative phase of the healing response to begin.

Wound healing consists of several distinct phases, all of which can be affected at the cellular level by LLLT. The initial, pro-inflammatory and vaso-active phases of inflammation include clotting of any cut blood vessels and deposition of a platelet plug, after which the site is infiltrated by neutrophils and macrophages.[25] The second phase of wound healing involves proliferation, with the formation of granulation tissue as a result of new blood vessel growth. Direct evidence for enhanced collagen gene expression both in skin fibroblast cultures in vitro, as well as in animal models of wound healing in vivo, has been presented.[26]

A final aspect of the effect of LLLT on cells relates to the effects of laser light on the cytoskeleton. Several studies have suggested that LLLT can modulate cell behavior by causing re-arrangements of the cytoskeleton.[27,28]

Faster wound closure is of great importance in compromised patients, such as diabetics, and patients undergoing treatment for malignancies. Because LLLT can enhance the release of growth factors from fibroblasts, and can stimulate cell proliferation, it is able to improve wound healing in such compromised patients. Histological studies have demonstrated that laser irradiation improves wound epithelialization, cellular content, granulation tissue formation, and collagen deposition in laser-treated wounds, compared to untreated sites $[29,30]$.These findings have been confirmed in oral mucosal wound healing in clinical studies in humans.[31]

\section{Effects Of Low Level Laser Therapy On Bone Cells}

In the laboratory setting, LLLT using a HeNe laser exerts pronounced effects on proliferation, differentiation and calcification of cultured osteoblastic cells, although there is a specific therapeutic window for these effects. Cell proliferation and DNA synthesis are increased by LLLT only when the cells are in a phase of active growth. LLLT causes increased accumulation of calcium and accelerates calcification in vitro. If the in vivo parallel holds true ,LLLT of healing sites within bone would be expected to increase bone deposition and promote bone regeneration .

In a study of wound healing after tooth extraction in a rat model, LLLT delivered on a daily basis for one week using a gallium-aluminium-arsenide ( $\mathrm{Ga} \mathrm{Al} \mathrm{As)} \mathrm{laser,} \mathrm{both} \mathrm{increased} \mathrm{fibroblast} \mathrm{proliferation} \mathrm{and}$ accelerated formation of bone matrix were found.[32]However, studies of the influence of LLLT on bone and connective tissue regeneration in the palate in a canine animal model failed to find an effect. While at first glance this would suggest major species variations in the response of bone cells to to LLLT, in the case in point irradiation levels were low and LLLT treatments were administered every second day rather than daily. Whether LLLT exerts positive results on bone regeneration following tooth extractions in humans remains controversial, although there are reports that the formation of granulation tissue during post-extraction healing is accelerated.[33]

For the treatment of intrabony defects, the use of barrier membranes and different types of grafting materials are usually indicated. In the study of effect of LLLT on the healing of bone defects associated with autologous bone grafts, bone remodelling was both quantitatively and qualitatively more evident in irradiated animals than in non irradiated animals[34].The association of matrix protein derivative with the LLLT irradiation has shown a reduction in post operative pain, which suggests that LLLT may improve the effects of matrix protein derivative by reducing post operative complications [35].LLLT biostimulation of bone tissue attachment to implant surfaces has also been reported. It has been shown that LLLT influences the expression of osteoprotegerin , receptor activator of nuclear factor $\mathrm{Kb}$ ligand and receptor activator of nuclear factor $\mathrm{k} \mathrm{B}$, and results in the expansion of bone cells metabolic activity.[36,37]

\section{Low Level Laser Therapy And Analgesia}

The ability of LLLT to exert analgesic effects has historically been a major clinical application of the technique. In vivo studies of the analgesic effect of LLLT on nerves supplying the oral cavity have demonstrated that LLLT decreases the firing frequency of nociceptors, with a threshold effect long-standing post -surgical IDN injury were assessed.[38,39]LLLT involved treatment along the distribution of the nerve for a total of 20 treatments. Control subjects received placebo LLLT. The degree of mechanoreceptor impairment and thermal sensitivity disability was comparable in test and control groups before treatment .Following LLLT, the test group showed a significant improvement in mechanoreceptor sensory testing, as well as a subjective improvement in sensory function, indicating that LLLT can improve mechanoreceptor perception in longstanding sensory aberrations in the IDN. However, there was no significant improvement in thermal responses in either group. 


\section{Antimicrobial Photodynamic Therapy}

Differently from high-power lasers, low-power lasers do not increase tissue temperature.[40]Thus, when used alone the same antimicrobial effect as that of high-power lasers in periodontitis active sites cannot be expected.[41]The antimicrobial effect low-power lasers is achieved by association with extrinsic photosensitizers, which results in the production of highly reactive oxygen species[42] that cause damage to membranes, mitochondria and DNA, culminating in the death of the microorganisms.[43-45]This is the process of aPDT, and its use is being increasingly studied with the aim of complementing the microbial reduction achieved by conventional mechanical periodontal therapy.

\section{Laser Curettage}

Both the Nd: YAG and gallium-arsenide (or diode) lasers are promoted for curettage.

\section{Low Level Laser Therapy And Neural Tissue}

LLLT has also been proven to reduce pain in patients suffering from post-herpetic neuralgia, from cervical dentinal hypersensitivity [46], or from periodontal pain during orthodontic tooth movement [47].LLLT may also be of benefit in treating TMJ disorders.

\section{Low Level Laser Therapy Equipment}

Semiconductor diode lasers are compact and have high conversion efficiency from electrical energy to laser energy. Unlike He-Ne lasers, semiconductor laser diodes do not require a high voltage supply, and so can be used in portable, battery-operated devices. It is also possible to pulse the light at various frequencies using simple external circuitry. Laser diodes have a typical life-expectancy of between 1,00,000 and 6,00,000 hours.[48]Semiconductor diode lasers are generally variants of either Aluminium:Gallium:Arsenide(AlGaAs) which emit in the near infrared spectrum(wavelength700-940nm),or

Indium: Gallium: Arsenide: Phosphorous (InGaAs) devices which emit in the red portion of the visible spectrum range (wavelength 600-680nm).The Beam Profile from a typical diode laser is rectangular, with a high divergence on the long axis and low divergence on short axis. Laser units used for LLLT are generally classified as Class 3 and $3 \mathrm{~b}$ in terms of the optical hazards which they pose to staff and patients. A monochromator will readily distinguish between a true laser diode and a LED.

\section{Conclusion}

Based on results of reviewed articles, low intensity laser therapy can accelerate bone healing in extraction sites, bone fracture defects and distraction osteogenesis in animal models. The mechanism of action might be through stimulation of cellular proliferation and differentiation and acceleration of the healing process. Further trials of new LLLT applications in dentistry should make use of standardized, validated outcomes, and should explore how the effectiveness of the LLLT protocol used may be influenced by wavelength, treatment duration, dosage, and the site of application.

\section{References}

[1]. Mester E, Mester AF, Mester A. The biomedical effects of laser application. Lasers Surg Med. 1985; 5(1):31-9. y of semiconductor laser application as an adjunct to conventional scaling and root planing. Lasers Surg Med 2005; 37:350-5.

[2]. Moritz A, Schoop U, Goharkhay K, Schauer P, Doertbudak O, Wernisch J, et al. Treatment of periodontal pockets with a diode laser. Lasers Surg Med 1998; 22:302-11. 8

[3]. Kreisler M, Al Haj H, d'Hoedt B. Clinical efficacy of semiconductor laser application as an adjunct to conventional scaling and root planning. Lasers Surg Med 2005; 37:350-5.

[4]. Karu TI. Photobiology of low-power laser effects. Hlth Phys 1989:56:691-704.

[5]. Karu TI. Photobiology of low-power laser therapy. London: Harwood Academic Publishers. 1989

[6]. Qadri T, Miranda L, Tuner J, Gustafsson A (2005) The short term effects of low-level lasers as adjunct therapy in the treatment of periodontal inflammation. J Clin Periodontol 32 (7):714-719.

[7]. Qadri T, Bohdanecka P, Tuner J, Miranda L, Altamash M, Gustafsson A (2007) The importance of coherence length in laser phototherapy of gingival inflammation: a pilot study. Lasers Med Sci 22(4):245-251.

[8]. Ribeiro IW, Sbrana MC, Esper LA, Almeida AL (2008) Evaluation of the effect of the GaAlAs laser on subgingival scaling and root planing. Photomed Laser Surg 26(4):387-391.

[9]. Ozawa Y, Shimizu N, Abiko Y (1997) Low-energy diode laser irradiation reduced plasminogen activator activity in human periodontal ligament cells. Lasers Surg Med 21(5):456-463

[10]. Pejcic A, Zivkvic V (2007) Histological examination of gingival treated with low-level laser in periodontal therapy. J Oral Laser Appl 71(1):37-43

[11]. Shimizu N, Yamaguchi M, Goseki T, Shibata Y, Takiguchi H, Iwasawa T, Abiko Y (1995) Inhibition of prostaglandin e2 and interleukin 1-beta production by low-power laser irradiation in stretched human periodontal ligament cells. J Dent Res 74(7):13821388

[12]. Grzesik WJ, Narayanan AS (2002) Cementum and periodontal wound healing and regeneration. Crit Rev Oral Biol Med 13 (6):474-484

[13]. Pitaru S, McCulloch CA, Narayanan SA (1994) Cellular origins and differentiation control mechanisms during periodontal development and wound healing. J Periodontal Res 29(2):81-94 
[14]. Kreisler M, Christoffers AB, Willershausen B, d'Hoedt B (2003) Effect of low-level GaAlAs laser irradiation on the proliferation rate of human periodontal ligament fibroblasts: an in vitro study. J Clin Periodontol 30(4):353-358

[15]. Loevschall H, Arenholt-Bindslev D (1994) Effect of low level diode laser irradiation of human oral mucosa fibroblasts in vitro. Lasers Surg Med 14(4):347-354

[16]. Yu W, Naim JO, Lanzafame RJ (1994) the effect of laser irradiation on the release of bFGF from 3T3 fibroblasts. Photochem Photobiol 59(2):167-170

[17]. Almeida-Lopes L, Rigau J, Zangaro RA, Guidugli-Neto J, Jaeger MM (2001) Comparison of the low level laser therapy effects on cultured human gingival fibroblasts proliferation using different irradiance and same fluence. Lasers Surg Med 29(2):179-184.

[18]. Pereira AN, Eduardo Cde P, Matson E, Marques MM (2002) Effect of low-power laser irradiation on cell growth and procollagen synthesis of cultured fibroblasts. Lasers Surg Med 31(4):263-267.

[19]. Azevedo LH, de Paula Eduardo F, Moreira MS, de Paula Eduardo C, Marques MM (2006) Influence of different power densities of LILT on cultured human fibroblast growth: a pilot study. Lasers Med Sci 21(2):86-89.

[20]. Moore P, Ridgway TD, Higbee RG, Howard EW, Lucroy MD (2005) Effect of wavelength on low-intensity laser irradiation stimulated cell proliferation in vitro. Lasers Surg Med 36(1):8-12.

[21]. Kreisler M, Christoffers AB, Al-Haj H, Willershausen B, d'Hoedt B (2002) Low level 809-nm diode laser-induced in vitro stimulation of the proliferation of human gingival fibroblasts. Lasers Surg Med 30(5):365-369.

[22]. Khadra M, Lyngstadaas SP, Haanaes HR, Mustafa K (2005) Determining optimal dose of laser therapy for attachment and proliferation of human oral fibroblasts cultured on titanium implant material. J Biomed Mater Res A 73(1):55-62.

[23]. Pourzarandian A, Watanabe H, Ruwanpura SM, Aoki A, Ishikawa I (2005) Effect of low-level Er:YAG laser irradiation on cultured human gingival fibroblasts. J Periodontol 76(2):187- 193.

[24]. Yu W, Naim JO, Lanzafame RJ. The effect of laser irradiation on the release of bFGF from 3T3 fibroblasts. Photochem Photobiol. 1994:59:167-170.

[25]. Walsh LJ, Murphy GF. The role of adhesion molecules in cutaneous inflammation and neoplasia. J Cutan Pathol 1992:19:161-171

[26]. Abergel RP, Lyons RF, Castel JC, Dwyer RM, Uitto J. Biostimulation of wound healing by lasers: experimental approaches in animal models and in fibroblast cultures. J Dermatol Surg Oncol. 1987:13:127-133

[27]. Noble PB, Shields ED, Blecher PDM, Bentley KC. Locomotory characteristics of fibroblasts within a three-dimensional collagen lattice: Modulation by a Helium/Neon soft laser. Lasers Surg Med 1992:12:669-674.

[28]. Pourreau-Schneider N, Ahmed A, Soudry M, Jacquemier J, Kopp F, Franquin JC, Martin PM. Helium-Neon laser treatment transforms fibroblasts into myofibroblasts. Am J Pathol 1990:137:171-178

[29]. Yu W, Naim JO, Lanzafame RJ. Effects of photostimulation on wound healing in diabetic mice. Lasers Surg Med 1997:20:56-63

[30]. Lyons RF, Abergel RP, White RA, Dwyer RM, Castel JC, Uitto J. Biostimulation of wound healing in vivo by a helium-neon laser. Ann Plast Surg. 1987:18(1):47-50.

[31]. Marei MK, Abdel-Meguid SH, Mokhtar SA, Rizk SA. Effect of low-energy laser application in the treatment of denture-induced mucosal lesions. J Prosthet Dent. 1997:77(3):256-264.

[32]. Takeda Y. Irradiation effect of low-energy laser on alveolar bone after tooth extraction. Experimental study in rats. Int J Oral Maxillofac Surg 1988:17:388-391.

[33]. Wahl G, Bastanier S. Soft laser in postoperative care in dentoalveolar treatment. ZWR 1991:100:512-515.

[34]. Weber JB, Pinheiro AL, de Oliveira MG, Oliveira FA, Ramalho LM (2006) Laser therapy improves healing of bone defects submitted to autologous bone graft. Photomed Laser Surg 24 (1):38-44.

[35]. Ozcelik O, Cenk Haytac M, Seydaoglu G (2008) Enamel matrixderivative and low-level laser therapy in the treatment of intrabony defects: a randomized placebo-controlled clinical trial. J Clin Periodontol 35(2):147-156.

[36]. Kim YD, Kim SS, Hwang DS, Kim SG, Kwon YH, Shin SH, Kim UK, Kim JR, Chung IK (2007) Effect of low-level laser treatment after installation of dental titanium implant - immunohistochemical study of RANKL, RANK, OPG: an experimental study in rats. Lasers Surg Med 39(5):441-450.

[37]. Lopes CB, Pinheiro AL, Sathaiah S, da Silva NS, Salgado MA (2007) Infrared laser photobiomodulation (lambda $830 \mathrm{~nm}$ ) on bone tissue around dental implants: a Raman spectroscopy and scanning electronic microscopy study in rabbits. Photomed Laser Surg 25(2):96-101.

[38]. Kitsmaniuk ZD, DemochkoVB, Popovich VI. The use of low energy lasers for preventing and treating postoperative and radiation induced complications in patients with head and neck tumors. Vopr Onkol 1992:8:980-986

[39]. Mezawa S, Iwata K, Naito K, Kamogawa H. The possible analgesic effect of soft laser irradiation on heat nociceptors in the cat tongue. Arch Oral Biol 1988:3:693-694

[40]. Dickers B, Lamard L, Peremans A, Geerts S, Lamy M, Limme M, Rompen E, de Moor RJ, Mahler P, Rocca JP, Nammour S (2009) Temperature rise during photo-activated disinfection of root canals. Lasers Med Sci 24(1):81-85.

[41]. Ishikawa I, Aoki A, Takasaki AA (2004) Potential applications of Erbium:YAG laser in periodontics. J Periodontal Res 39 (4):275285.

[42]. Wainwright M (1998) Photodynamic antimicrobial chemotherapy (PACT). J Antimicrob Chemother 42(1):13-28

[43]. Bhatti M, MacRobert A, Meghji S, Henderson B, Wilson M (1998) A study of the uptake of toluidine blue O by Porphyromonas gingivalis and the mechanism of lethal photosensitization. Photochem Photobiol 68(3):370-376

[44]. Bhatti M, Nair SP, Macrobert AJ, Henderson B, Shepherd P, Cridland J, Wilson M (2001) Identification of photolabile outer membrane proteins of Porphyromonas gingivalis. Curr Microbiol 43(2):96-99.

[45]. Harris F, Chatfield LK, Phoenix DA (2005) Phenothiazinium based photosensitisers - photodynamic agents with a multiplicity of cellular targets and clinical applications. Curr Drug Targets 6(5):615-627

[46]. Sandford MA, Walsh LJ. Thermal effects during desensitization of teeth with gallium-aluminiumarsenide lasers. Periodontol 1994:15: 25-30.

[47]. Wahl G, Bastanier S. Soft laser in postoperative care in dentoalveolar treatment. ZWR 1991:100:512-515

[48]. Wheeler J, Slater N. Squaring off: The He-Ne vs red diode. Lasers Optron 1990:16: 38-44. 